\title{
Teaching Paediatrics in Iraq Amid the COVID-19 Pandemic
}

\author{
تدريس طب الأطفال في العراق في خِضَم جائحة كوفيد-19
}

\section{Dear Editor,}

On 11 March 2020, World Health Organization announced novel coronavirus disease (COVID-19) a pandemic after its spread from Wuhan, China to many parts of the world infecting hundreds of thousands of people. Due to its quick emergence, spatial extent and grave aftermaths, the COVID-19 pandemic can be considered a once-ina-century global disaster. It has imposed negative impacts on various environmental, social, economic and health aspects. ${ }^{1,2}$

The influence of COVID-19 on medical education is multifaceted including disrupting routines in medical faculties and hospitals, cancelling clerkships that are essential for relationship building and skill acquisition and students' loss of the opportunity for personal development through conference presentations which is essential in differentiating applicants during the process of residency application. Lost opportunities could have a critical impact on students' career trajectory. ${ }^{3}$ Students are also more likely to be affected in terms of changes in grading, cessation of clinical rotations, alterations in medical licensing examinations and consequences on mental health status. $^{4}$

In Iraq, medical education has been disrupted due to the antecedent decades of conflict, corruption, violence, poor administration and under-investment in academic teaching. ${ }^{5}$ Substantial efforts were geared to reform medical curriculum, promote students skills and plan opportunities for development. ${ }^{6}$ However, the emergence of COVID-19 in Iraq in February 2020 has curtailed these efforts. The Government of Iraq ordered a lockdown as the numbers of positive COVID-19 cases continued to rise. Universities and medical colleges have closed. Students have stayed at home and medical teaching has been suspended. ${ }^{7}$ In a step to continue learning and save the academic year, in March 2020 the Ministry of Higher Education and Scientific Research in Iraq decided to replace in-person classes with online equivalents. ${ }^{8}$

In the process of online teaching pediatrics (OTP) in Iraq, teaching staff have employed Google Classroom (Google, LLC, Mountain View, California, USA) to deliver audio-visual lectures and educational medical videos and images as well as set online discussions with students on various topics in paediatrics. Similarly, students have presented seminars and taken part in formative and summative assessments.

Challenges facing OTP in Iraq are manifold. Disrupted infrastructures, in particular disturbed electricity distribution, slow internet services, impaired technical skills, time limits and the absence of institutional strategies are the major key barriers influencing the implementation of OTP. As students are not accustomed to the process of digital preparation to undertake assessments which usually requires clinical exposure, disappointing effects on examination performance and competency are expected. Despite recruitment of teaching staff in workshops and seminars on the process of online teaching, teaching staff were not fully competent in developing and delivering online content. Poor technical skills in a substantial number of students resulted in negative attitudes towards e-learning environments. These challenges were more devastating for final year students waiting for their final assessments. They lost clinical clerkships and electives that are important determinants of allocation.

Despite all challenges encountered in OTP, it has been possible to sustain, at least to some extent, students' knowledge and collaborative essence as well as commitment and dedication to paediatrics. In the light of the continuing COVID-19 pandemic, further ingenuities for teaching students are expected to emerge.

The COVID-19 pandemic has dramatically changed the landscape of medical education in Iraq. The crisis has actually taught many lessons. First, online teaching, irrespective of its limitations (i.e. no training, little preparation and insufficient bandwidth), is fruitful and advantageous in terms of comfort, accessibility, offering more time for studying or external commitments due to lack of commute, welcoming environment to students with illness or physical disability and encouraging student-centred learning. Second, everything is unpredictable and we must be ready to confront challenges during the current as well as future crises. Though this abrupt crisis did not give us 
much time to plan, it is important to understand that meticulous planning is key. Third, students should possess certain skills such as critical thinking, problem-solving and importantly adaptability to overcome crises. Academic institutions need to set resilience in their systems to prioritise the presence of these skills in their students. Fourth, integrating information technology in medical education is a worthy investment. It is expected to become more used in the near future as online teaching will eventually become the core element of education.

Faculty members of the Department of Paediatrics at Al-Kindy College of Medicine, University of Baghdad, are planning to comprehensively evaluate OTP at the end of academic year 2020. For successful online teaching, it is recommended to provide support to infrastructures (network, electricity and devices), platforms (stability, interaction and the ability to improve) and preparedness of educators (educational workshops) and students (proper technique and learning support). It is also recommended that institutions concentrate on increasing the efficiently of the use of technology by looking into a technology with less procurement and maintenance costs but with the ability to enhance effective educational processes. Training the faculty and educators on employing new online modalities and developing lesson plans with decreased cognitive load and increased interactivities is crucial. As online teaching is not a substitute for face-to-face (i.e. traditional) teaching, blended teaching utilising both types is becoming the new norm during the academic year 2020/2021 in Iraq and it might continue even after the subsidence of the COVID-19 pandemic.

\section{Mahmood D. Al-Mendalawi}

Department of Paediatrics, Al-Kindy College of Medicine, University of Baghdad, Baghdad, Iraq.

E-mail:mdalmendalawi@yahoo.com

\section{References}

1. Sarkodie SA, Owusu PA. Global assessment of environment, health and economic impact of the novel coronavirus (COVID-19). Environ Dev Sustain 2020:1-11. https://doi.org/10.1007/s10668-020-00801-2.

2. Smith BJ, Lim MH. How the COVID-19 pandemic is focusing attention on loneliness and social isolation. Public Health Res Pract 2020; 30:3022008. https://doi.org/10.17061/phrp3022008.

3. Ferrel MN, Ryan JJ. The impact of COVID-19 on medical education. Cureus 2020; 12:e7492. https://doi.org/10.7759/cureus.7492.

4. Akers A, Blough C, Iyer MS. COVID-19 implications on clinical clerkships and the residency application process for medical students. Cureus 2020; 12:e7800. https://doi.org/10.7759/cureus.7800.

5. Al-Shamsi M. Medical education in Iraq: Issues and challenges. Int J Med Educ 2017; 8:88-90. https://doi.org/10.5116/ijme.58b1.c927.

6. Al-Mendalawi MD. Medical curricular reform in Iraq. Clin Teach 2018; 15:262-4. https://doi.org/10.1111/tct.12700.

7. Government of Iraq. COVID-19: Iraqi government announces new measures. From: https://gds.gov.iq/covid-19-iraqi-governmentannounces-new-measures/ Accessed: Nov 2020.

8. Central library. Notice from the Ministry of Higher Education and Scientific Research. From: https://www.uomosul.edu.iq/news/en/ libCentral/55114 Accessed: Nov 2020. 